4. Vidal-Rubio S.L., Balanzá-Martínez V., Cuenca M, et al. (2018), "Duration of euthymia and predominant polarity in bipolar disorder", J Affect Disord; 241: 356-359.

5. Bùi Quang Huy (2018), Rối loạn cảm xúc lưỡng cực chẩn đoán và điều trị, Nhà xuất bản Y học, Hà Nồi, trang 7-84.

6. Cao Tiến Đức (2017), Rối loạn khí sắc. Giáo trình Tâm thần học, Nhà xuất bản Quân đội Nhân dân, Hà Nội, trang 201-219.
7. Quested D.J., Gibson J.C., Sharpley A.L et al., (2021), "Melatonin In Acute Mania Investigation (MIAMI-UK). A randomized controlled trial of addon melatonin in bipolar disorder", Bipolar Disord; 23(2): 176-185

8. Xu L., Lu Y., Yang Y. et al. (2015), "Olanzapinevalproate combination versus olanzapine or valproate monotherapy in the treatment of bipolar I mania: a randomized controlled study in a Chinese population group", Neuropsychiatr Dis Treat; 11: 1265-1271.

\title{
KẾT QUẢ ĐIỀU TRI BẢO TỒN VIÊM TUYẾN NƯỚC BỌT MANG TAI MẠN TÍNH
}

\section{TÓM TẮT}

Các phương pháp điều trị bảo tồn viêm tuyến nước bot mang tai mạn tính ngày càng được quan tâm do điều trị phấu thuật cắt tuyên nước bợ có chi phí cao, nhiều biến chứng; bên cạnh đó, khả năng của các tuyến phục hồi chức năng hoặc không có triệu chứng sau khi loại bỏ tắc nghẽn đã được chứng minh bằng thực nghiểm và lâm sàng. Mục tiêu: Mô tả kết quả điểu trị bảo tồn viêm tuyến nước bot mang tai mạn tính trong một số tài liệu đã công bổ. Đối tượng và phương pháp nghiên cứu: Tổng quan và phân tích dữ liệu về kết quả điều trị bảo tồn viêm tuyến nước bọt mang tai mạn tính từ các bài báo, luận văn, luận án trên trang cở sở dữ liệu Pubmed, Google Scholar, EBSCOhost Research Databases. Kết quả: Tổng hợp trong 155 nghiên cứu lọc tên bài và phần giới thiệ̉u trên 3 trang cơ sở dữ liệu: Pubmed, Google Scholar, ESBCO host Research Databases được 32 nghiên cứu. Tiếp tục đánh giá chi tiết các tài liêu chon đước 5 tài liệu đạt tiêu chuẩn đưa vào phân tích: 3 nghiên cứu tiển cứu và 2 nghiên cứu thử nghiệm lâm sàng ngẫu nhiên có đối chứng. Kết quả phần tích cho thấy: điêu trị bảo tồn viêm tuyến nước bot mang tai mạn tính bằng bơm rửa hệ thống ống tuyến, có kết hợp với các chất chống viêm, kháng khuẩn có hiệu quả cao, với kết quả cải thiện chỉ số VAS rõ rệt so với trước điều trị và tỳ lệ tái phát thấp. Bệnh nhân được bớm rửa hể thống ổng tuyến bằng penicillin có kết quả điều trị ổn định, không tái phát sau 8 năm. Kết hợp nội soi và bơm rửa hệ thổng ống tuyến với betamethason cải thiên chỉ số VAS tốt hơn so với chỉ nội soi ống tuyến. Kết luận: Điêu trị bảo tồn viêm tuyến nước bọt mang tai mạn tính bằng bơm rửa hệ thống ống tuyến, có kểt hợp với các chất chống viêm, kháng khuẩn có hiệu quả cao, với kết quả cải thiện chỉ số VAS rõ rệt so với

1 Viện Đào tạo Răng hàm mặt, Trường Đại học Y Hà Nội 2 Trường Đại học Y Dược - Đại học Quốc Gia Hà Nội

Chịu trách nhiệm chính: Đặng Thị Hường

Email: huong03111982@gmail.com

Ngày nhận bài: 23.6.2021

Ngày phản biên khoa họ: 20.8.2021

Ngày duyệt bài: 27.8.2021
Từ khóa: kết quả, điều trị bảo tồn, viêm tuyến nước bọt mang tai mạn tính.

\section{SUMMARY}

\section{RESULTS OF CONSERVATIVE TREATMENT \\ OF CHRONIC RECURRENT PAROTITIS}

The conservative treatment methods for chronic recurrent parotitis are increasingly interested due to the high cost and complications of surgical treatment; In addition, the ability of the glands to restore function or be asymptomatic after removal of the obstruction has been demonstrated experimentally and clinically. Objectives: Describe the results of conservative treatment of chronic recurrent parotitis. Materials and methods: Review and analysis of data on conservative treatment of chronic recurrent parotitis from articles, theses and dissertations on Pubmed database, Google Scholar, EBSCOhost Research Databases. Results: Synthesized in 155 studies filtering the title and introduction on 3 databases: Pubmed, Google Scholar, ESBCO host Research Databases were 32 studies. Continuing to evaluate the literature in detail, 5 documents met the criteria for analysis: 3 prospective studies and 2 randomized controlled clinical trials. The results of the analysis showed that: conservative treatment of chronic recurrent parotitis with ductal irrigation, in combination with anti-inflammatory and antibacterial agents, is highly effective, with improved VAS index was markedly compared to before treatment and the recurrence rate was low. The patient was irrigated with penicillin with stable treatment results, no recurrence after 8 years. Combining sialendoscopy and irrigation of the ductal system with betamethasone improves VAS better than sialendoscopy alone. Conclusion: Conservative treatment of chronic parotitis with ductal irrigation, combined with antiinflammatory and antibacterial agents is highly effective, with significant improvement in VAS index compared with with pre-treatment and low recurrence rate.

Keywords: outcome, conservative treatment, chronic recurrent parotitis. 


\section{I. ĐĂT VẤN ĐỀ}

Viêm tuyến nước bọt mang tai mạn tính là một tình trạng viêm đặc trưng bởi sưng một bên hoặc hai bên tuyến nước bọt mang tai định kỳ hoặc dai dẳng kèm theo đau vùng tuyến nước bọt mang tai, là một tình trạng lâm sàng khó chịu, ảnh hưởng đến bệnh nhân ở nhiều độ tuổi.

Nguyên nhân nguyên phát của viêm tuyến nước bọt mang tai mạn tính được cho là do giảm tiết nước bot hoăc ứ đong, tắc nghẽn nước bot, do đó mục tiêu điều trị đầu tiên là làm tăng tiết nước bọt, loại bỏ các tắc nghẽn, ứ đọng trong hệ thống ổng tuyến. Các phương pháp điều trị bảo tồn luôn được lựa chọn là phương pháp điều tri đầu tiên đối với bệnh nhân viêm tuyến nước bọt mang tai mạn tính do đáp ứng được mục tiểu điều trị, có hiệu quả bước đầu cao, nguy cơ biến chứng thấp, chi phí điều trị thấp, dễ chấp nhận đối với cả bệnh nhân và bác sĩ. Tuy nhiên, hiệu quả của điều trị bảo tồn viêm tuyến nước bọt mang tai mạn tính hiện vẫn chưa được đánh giá chính xác và còn nhiều tranh cãi.

Xuất phát từ những lý do trên, chúng tôi thực hiện nghiên cứu này với mục tiêu: Mô tả kết quả điều trị bảo tồn viêm tuyến nước bọt mang tai mạn tính trong một số tài liệu đã công bố.

\section{II. ĐỐI TƯợNG VÀ PHƯƠNG PHÁP NGHIÊN CỨU}

2.1 . Đối tượng: Các bài báo, luận văn, luận án trên trang cơ sở dữ liệu Pubmed, Google Scholar, EBSCOhost Research Databases.

Tiêu chuẩn lựa chọn:

* Theo tiêu chí PICO:

- Population/Patient (Đối tượng): Bệnh nhân viêm tuyến nước bọt mang tai mạn tính.

- Intervention (can thiệp): Điều trị bảo tồn không phẫu thuật.

- Control/Comparison: Sự thay đổi các triệu chứng, tỷ lệ tái phát sau điều trị so với trước điều trị.

- Outcome: Kết quả điều trị bảo tồn viêm tuyến nước bot mang tai mạn tính.

\section{Tiêu chuẩn loại trừ:}

- Các bài báo không cung cấp đủ thông tin phục vụ cho nghiên cứu.

- Các bài dạng tổng quan.

\subsection{Phương pháp nghiên cứu:}

Các bước tiến hành nghiên cứu:

Bước 1: Xác định câu hỏi nghiên cứu: Điều trị bảo tồn viêm tuyến nước bọt mang tai mạn tính có thể có kết quả như thế nào?

Bước 2: Xây dựng tiêu chuẩn lựa chọn và loại trừ đối tượng.
Bước 3: Phương pháp, chiến lược tìm kiếm và nguồn dữ liệu

- Nguồn thông tin tìm kiếm: trang cơ sở dữ liệu Pubmed, Google Scholar, EBSCOhost Research Databases.

- Từ khóa tìm kiếm online: Conservative treatment of chronic parotitis, Conservative treatment of chronic recurrent parotitis, treatment of chronic parotitis, treatment of chronic recurrent parotitis.

Bước 4: Lựa chọn nghiên cứu

Bước 5: Đánh giá chất lượng nghiên cứu

Bước 6: Trích xuất dữ liệu, đo lường kết quả

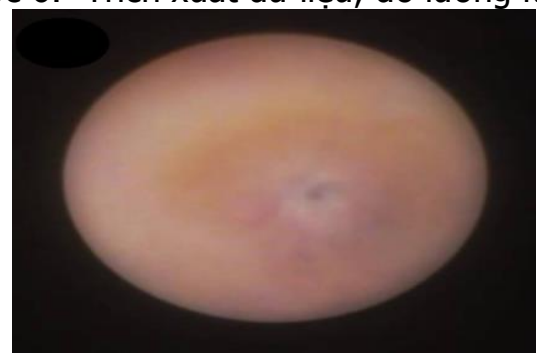

Hình 1: Hình ảnh nội soi hê thống ống tuyến mang tai cho thấy tắc ống tuyến

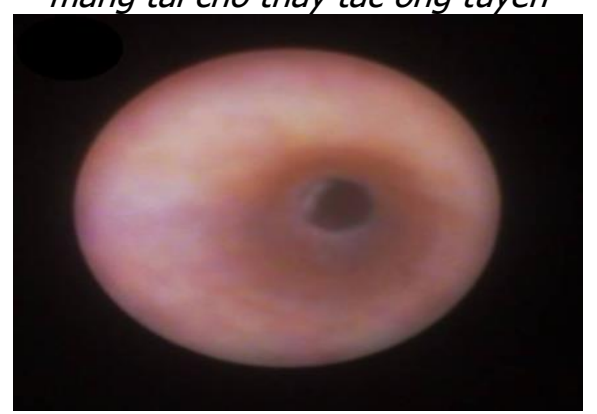

Hình 2: Nội soi hệ thống ống tuyến mang tai sau điều trị: vị trí tắc nghẽn đã được nong rộng

\section{KẾT QUẢ VÀ BÀN LUÂ̂N}

Tìm trên 3 trang cơ sở dữ liệu: Pubmed, Google Scholar, ESBCO host Research Databases được 155 tài liệu tham khảo. Sau khi loại bỏ các tài liệu trùng lặp, tiếp tục đánh giá chi tiết tiêu đề và tóm tắt của các tài liệu, có 32 tài liệu đủ điều kiện đọc toàn văn. Sau khi đọc toàn bộ tài liệu, chọn được 5 tài liệu đạt tiêu chuẩn đưa vào phân tích.

3.1 Đặc điểm nghiên cứu. Đặc điểm của các bài báo được đưa vào tổng quan này được trình bày trong bảng 1 . Tổng số 80 bệnh nhẩn viêm tuyến nước bọt mang tai mạn tính được điều trị bảo tồn được phân tích trong 3 nghiển cứu tiển cứu và 2 nghiên cứu thử nghiệm lâm sàng ngẫu nhiên có đối chứng. 
Bảng 1: Các nghiên cứu đử tiêu chuẩn

\begin{tabular}{|c|c|c|c|c|c|}
\hline Tác giả & $\begin{array}{c}\text { Thiết kế } \\
\text { nghiến cứu }\end{array}$ & $\begin{array}{c}\text { Số lươnng } \\
\text { bệnh nhấn }\end{array}$ & Tuổi & Giới & $\begin{array}{c}\text { Thời gian } \\
\text { theo dõi }\end{array}$ \\
\hline $\begin{array}{c}\text { Antoniades D. et } \\
\text { al., 2004 [1] }\end{array}$ & Tiến cứu & 27 & $8-65$ & $\begin{array}{c}16 \text { nam, } \\
11 \text { nữ }\end{array}$ & 12 năm \\
\hline $\begin{array}{c}\text { Shacham R. et al., } \\
\text { 2011 [2] }\end{array}$ & Tiến cứu & 10 & $31-79$ & $\begin{array}{c}0 \text { nam, } \\
10 \text { nữ }\end{array}$ & 30 tháng \\
\hline $\begin{array}{c}\text { Roby BB et al., } \\
\text { 2015 [3] }\end{array}$ & Tiến cứu & 12 & $\begin{array}{c}6,7 \\
(3,5-16)\end{array}$ & $\begin{array}{c}58 \% \text { nam, } \\
42 \% \text { nữ }\end{array}$ & 12 tháng \\
\hline $\begin{array}{c}\text { Jokela J. et al., } \\
\text { 2017 [4] }\end{array}$ & $\begin{array}{c}\text { Thứ nghiệm lâm sàng } \\
\text { ngấu nhiên có đối chứng }\end{array}$ & 49 & $\begin{array}{c}53 \\
(21-75)\end{array}$ & $\begin{array}{c}33 \% \text { nam, } \\
67 \% \text { nữ }\end{array}$ & 12 tháng \\
\hline $\begin{array}{c}\text { Capaccio P. et al., } \\
\text { 2018 [5] }\end{array}$ & $\begin{array}{c}\text { Thứ nghiệm lâm sàng } \\
\text { ngấu nhiên có đối chứng }\end{array}$ & 22 & $69,4 \pm 10,2$ & $\begin{array}{c}13,6 \% \text { nam, } \\
86,4 \% \text { nữ }\end{array}$ & 6 tháng \\
\hline
\end{tabular}

3.2. Kết quả điêu trị bảo tồn viêm tuyến nước bọt mang tai mạn tính trong các tài liệu đã công bố

Bảng 2: Dữ liệu về kêt quả điều trị bảo tồn viêm tuyến nước bọt mang tai mạn tính

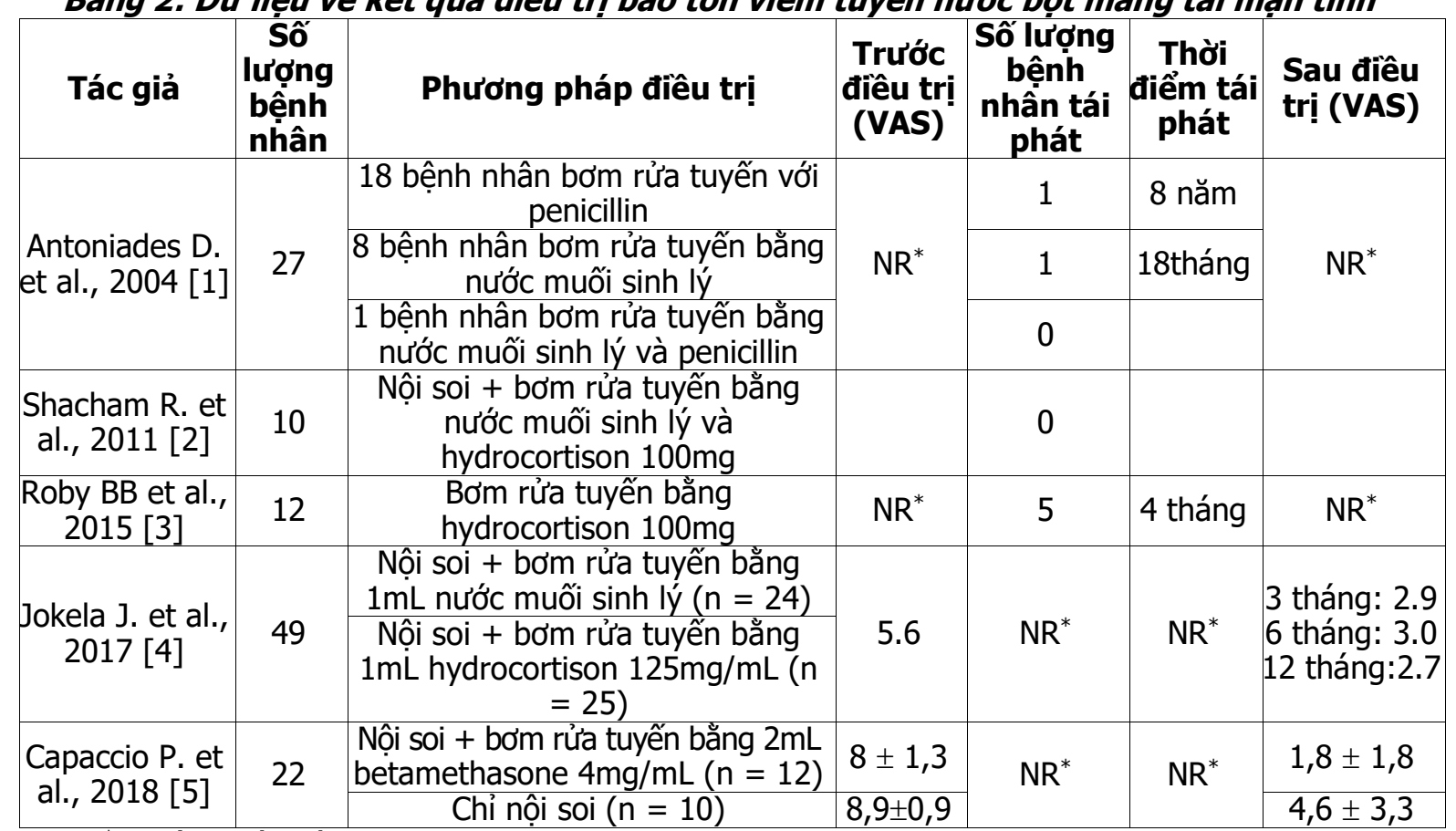

NR*: Không báo cáo

Tổng quan này đã đánh giá một số tài liệu liên quan đến kết quả điều trị bảo tồn viêm tuyến nước bọt mang tai mạn tính. Các nghiên cứu của các tác giả đều cho kết quả rằng điều trị bảo tồn viêm tuyến nước bọt mang tai mạn tính bằng bơm rửa hệ thống ống tuyến, có kết hợp với các chất chống viêm, kháng khuẩn có hiệu quả cao, với kết quả cải thiện chỉ số VAS rõ rệt so với trước điêuu trị và tỷ lệ tái phát thấp. Bệnh nhân được bơm rửa hệ thống ống tuyến bẳng penicillin có kết quả điểu trị ổn định, không tái phát sau 8 năm. Kết hợp nội soi và bơm rửa hệ thống ống tuyến với betamethason cải thiện chỉ số VAS tốt hơn so với chỉ nội soi ống tuyến.

Baurmash (2004) đề xuất rằng việc điều trị viêm tuyến mang tai mạn tính nên được hướng tới chống lại cả viêm tuyến bằng steroid cũng như protein huyết thanh kết tủa bằng cách loại bỏ nhanh chóng và hoàn toàn thông qua việc làm giãn nở, bơm rửa hệ thống ống tuyến và xoa bóp tuyến [6].

Antoniades và Harrison (2004), trong nghiên cứu so sánh tác dụng của bơm rửa ống tuyến bằng nước muối và penicillin với nước muối đơn thuần trong điều trị viêm tuyến mang tai mạn tính, đã kết luận rằng bơm rửa là yếu tố quan trong hơn trong điều trị viêm tuyến mang tai mạn tính [1].

Capaccio và cộng sự (2018) kết luận rằng sự kết hợp của nội soi ống tuyến sau đó bơm rửa 
steroid lặp đi lặp lại tại phòng khám ngoại trú đã mang lại kết quả tốt hơn so với nội soi ống tuyến đơn độc trong điều trị viêm tuyến nước bọt không rõ nguyên nhân tái phát [7]. Cùng một loại kết quả sơ bộ đã được tìm thấy trong một nghiên cứu trên 22 bệnh nhân mắc hội chứng Sjögren và sưng các tuyến nước bọt chính [5]. Sử dụng Steroid trong ống tuyến cũng được đánh giá và nhận thấy có hiệu quả ở những bệnh nhân bị viêm tuyến mang tai tái phát ở tuổi vị thành niên được điêu trị bằng truyên dịch hydrocortisone qua ống thông được đặt trong ống tuyến mang tai [3], và trong một nghiên cứu về tuyến nước bọt bị ảnh hưởng bởi bệnh tự miễn được điêu trị bằng nội soi ống tuyến và tiêm hydrocortisone trong ống tuyến [2]. Delagnes và cộng sự (2016) quan sát thấy rằng việc sử dụng triamcinolone bơm rửa đồng thời với nội soi ống tuyến có liên quan đến việc giải quyết triệu chứng tốt hơn ở những bệnh nhân bị viêm tuyến nước bọt mà không có sỏi nước bọt [8].

\section{KẾT LUÂN}

Điêuu trị bảo tồn viêm tuyến nước bọt mang tai mạn tính bằng bơm rửa hệ thống ống tuyến, có kểt hợp với các chất chống viêm, kháng khuẩn có hiệu quả cao, với kết quả cái thiện chỉ số VAS rõ rệt so với trước điều trị và tỷ lệ tái phát thấp.

\section{TÀI LIẸU THAM KHẢO}

1. Antoniades D, Harrison JD, Papanayotou $P$, et al. Treatment of chronic sialadenitis by intraductal penicillin or saline. J Oral Maxillofac Surg. 2004;62 (4):431-4. doi: 10.1016/j.joms.2003.07.007

2. Shacham $R$, Puterman $M B$, Ohana $N$, et al. Endoscopic treatment of salivary glands affected by autoimmune diseases. J Oral Maxillofac Surg. 2011; 69(2):476-481. doi: 10.1016/ j.joms.2010.10.002

3. Roby BB, Mattingly J, Jensen $E L$, et al. Treatment of juvenile recurrent parotitis of childhood: an analysis of effectiveness. JAMA Otolaryngol Head Neck Surg. 2015;141(2):126-9. doi: 10.1001/jamaoto.2014.3036

4. Johanna Jokela, Aaro Haapaniemi, Antti Mäkitie, Riitta Saarinen. Sialendoscopy in treatment of adult chronic recurrent parotitis without sialolithiasis. European Archives of OtoRhino-Laryngology. 2018; 275 (3):775-781. doi: 10.1007/s00405-017-4854-7

5. Capaccio $P$, Canzi $P$, Torretta $S$, et al. Combined interventional sialendoscopy and intraductal steroid therapy for recurrent sialadenitis in Sjogren's syndrome: results of a pilot monocentric trial. Clin Otolaryngol. 2018;43(1):96102. doi: 10.1111/coa.12911

6. Baurmash HD. Chronic recurrent parotitis: a closer look at its origin, diagnosis, and management. J Oral Maxillofac Surg. 2004; 62 (8):1010-1018. doi: 10.1016/j.joms.2003.08.041

7. Capaccio P, Torretta S, Di Pasquale D, Rossi V, Pignataro L. The role of interventional sialendoscopy and intraductal steroid therapy in patients with recurrent sine causa sialadenitis: a prospective cross-sectional study. Clin Otolaryngol. 2017;42(1):148-155. doi: 10.1111/coa.12681

8. Delagnes EA, Aubin-Pouliot $A$, Zheng $M$, et al. Sialadenitis without sialolithiasis: prospective outcomes after sialendoscopy-assisted salivary duct surgery. Laryngoscope. 2017;127(5):10731079. doi: 10.1002/lary. 26308

\section{PHÂN LOAI MÔ BÊNH HỌC SARCOM XƯƠNG NGUYÊN PHÁT THEO PHÂN LOAI CỦA TỔ CHỨC Y TẾ THẾ GIỚI (WHO) NĂM 2013 VÀ TİM HIỂU MỐI LIÊN QUAN VỚI TIÊN LƯợNG BỆNH}

\section{TÓM TẮT}

Mục tiêu: Phân loai mô bệnh học sarcom xương nguyên phát và tìm hiểu mối liên quan với tiên lượng bệnh trên các bệnh nhân sarcom xương tại bệnh viện K. Đối tượng và phương pháp nghiên cứu: Kết hợp hồi cứu và tiến cứu trên 123 bệnh nhân được chẩn đoán sarcom xương và điều trị tại bệnh viện K.

\footnotetext{
${ }^{1}$ Bênh viện $K$

${ }^{2}$ Trường Đại hoc Y Hà Nôi

Chịu trách nhiệm chính: Phạm Thị Hân

Email: phamthihan.bvk@gmail.com

Ngày nhận bài: 24.6.2021

Ngày phản biên khoa học: 23.8.2021

Ngày duyệt bài: 27.8.2021
}

\section{Phạm Thị Hân ${ }^{1}$, Tạ Văn Tờ ${ }^{1,2}$}

Kết quả: Trong 123 trường hợp, các típ mô bệnh học độ cao chiếm chủ yếu với $98,37 \%$ số ca. Trong số đó, dưới típ nguyên bào xương chiếm tỷ lệ cao nhất là $54,47 \%$. Tiếp đến là típ nguyên bào xớ, nguyên bào sụn và các típ mô học độ cao khác. Các típ mô học độ thấp chỉ chiếm $1,63 \%$. Sự khác biệt giữa các nhóm có ý nghĩa thống kê với $\mathrm{p}<<0,05$. Xác suất sống sót chung sau 5 năm là $41,7 \%(95 \% \mathrm{CI}=0,33-0,54)$. Phân típ mô bệnh học không có mối liên quan có ý nghĩa thống kê với xác suất sống sót $(p>0,05)$.

Ti̛ khóa: Sarcom xương nguyên phát, típ mô bệnh học, xác suất sống sót.

\section{SUMMARY \\ CLASSIFYING PRIMARY OSTEOSARCOMAS ACCORDING TO 2013 WORLD HEALTH}

